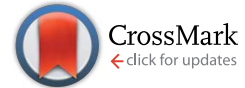

Cite this: RSC Adv., 2015, 5, 65932
Received 24th June 2015 Accepted 28th July 2015 DOI: $10.1039 / c 5 r a 12237 f$ www.rsc.org/advances

\section{Multifunctional ionic hybrid poly(propyleneimine) dendrimers surrounded by carbazole dendrons: liquid crystals, optical and electrochemical properties $\dagger$}

\author{
Susana Castelar, ${ }^{a}$ Pilar Romero, ${ }^{a}$ José-Luis Serrano, ${ }^{b}$ Joaquín Barberá*a \\ and Mercedes Marcos*a
}

Two novel series of dendrimers synthesised by the ionic grafting of poly(propylene imine) PPI- $\left(\mathrm{NH}_{2}\right)_{n}(n=$ $4,8,16,32,64$ primary amines on the surface) with bifunctional dendrons of two generations $(\mathrm{G} 1 \mathrm{COOH}$, $\mathrm{G} 2 \mathrm{COOH}$ ) derived from 2,2-bis(hydroxymethyl)propanoic acid (bis-MPA) were prepared. The dendrons contain a carboxyl group at their apex and electroactive carbazole groups and mesogenic units on their periphery. The occurrence of proton transfer from the carboxylic acid to the amine groups was confirmed by IR and NMR measurements. The liquid crystalline behavior has been investigated by means of differential scanning calorimetry (DSC), polarizing optical microscopy (POM) and X-ray diffractometry (XRD). All ionic dendrimers were liquid crystalline (nematic, smectic or columnar mesophases). The type of mesophase depends on the dendrimer generation as well as on the dendron generation. The electrochemical behavior of the ionic dendrimers was investigated by cyclic voltammetry (CV). Scanning electron microscopy (SEM) studies revealed that electrochemical deposition of the material on the conducting substrate takes place. The UV-vis absorption and emission properties of the ionic hybrid dendrimers have been investigated. All the compounds are luminescent at room temperature and the intensity is related to the number of carbazole units present in the molecule.

\section{Introduction}

Dendrimers are monodisperse, highly branched macromolecules that have attracted significant interest in material science and biomedicinal fields. ${ }^{1-4}$ Their unique architecture originates novel properties, such as better solubility and lower viscosity than their analogous linear polymers. Moreover the high density of functional groups contained in their structure allows the introduction of a higher number of active units with specific properties.

In these materials, using a similar approach to that used in side chain liquid crystals polymers (SCLCP), the incorporation of promesogenic units on the periphery of the dendrimeric

\footnotetext{
${ }^{a}$ Departamento de Química Orgánica, Facultad de Ciencias-Instituto de Ciencia de Materiales de Aragón, Universidad de Zaragoza-CSIC, 50009 Zaragoza, Spain. E-mail:mmarcos@unizar.es; jbarbera@unizar.es

${ }^{b}$ Departamento de Química Orgánica, Facultad de Ciencias, Instituto de Nanociencia de Aragón, Universidad de Zaragoza, 50009 Zaragoza, Spain

$\dagger$ Electronic supplementary information (ESI) available: Text giving more details about the employed techniques including reaction schemes and structures, optical studies, synthesis and characterization of the materials, and DSC data, figures showing the compound structure, NMR and IR spectra, and DSC curves, and optical data. See DOI: 10.1039/c5ra12237f
}

structures allow us to obtain liquid crystals dendrimers. ${ }^{5}$ The majority of these mesogenic dendrimers have been obtained using a covalent attachment of the molecules, ${ }^{6}$ but also the ionic attachment of molecules bearing a carboxylic group to the amine terminal groups of the poly(propylene imine) (PPI) and poly(amidoamine) (PAMAM) dendrimers has demonstrated to be an easy and versatile strategy to produce mesomorphic materials. ${ }^{7}$ Using this method the incorporation of different functional units could be used in order to prepare multifunctional materials for specific applications. Thus the incorporation of photoactive molecular units, such as carbazole, into liquid crystalline polymers may offer advantages over conventional polymers. ${ }^{8}$ It is important to take account that carbazole is one of the most familiar electron donors and it has been widely used in the design of fluorescent and hole-transporting materials. ${ }^{9}$ Thus Preece et al. ${ }^{\mathbf{1 0}}$ describe in 2001 the first columnar liquid crystal containing carbazole units and in 2002 Velasco et al. ${ }^{\mathbf{1 1}}$ describe the first carbazole-based lamellar liquid crystal system. Later other liquid crystals functionalized with carbazole units have been reported in the literature. ${ }^{12}$ In 2012 Manickam et al. have published an interesting review concerning carbazole-based photorefractive liquid crystal materials. ${ }^{13}$ 

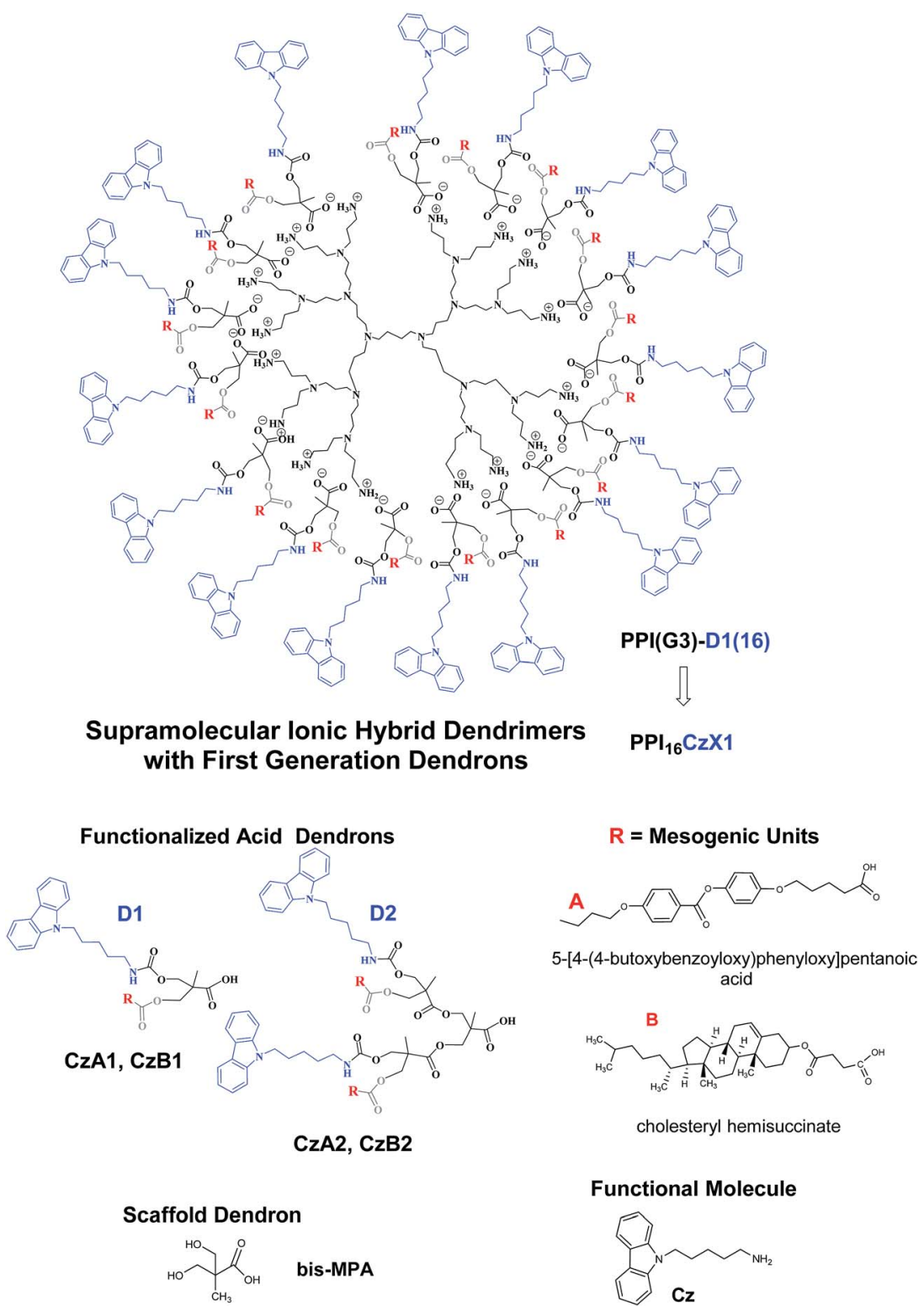

Scheme 1 Schematic representation and nomenclature of the reported dendrons $(\mathrm{C} z \mathrm{Xm})$ and dendrimers $(\mathrm{PPI})_{n} \mathrm{C} z \mathrm{Xm}$. The hybrid dendrimer with third generation of PPI G3 and a first generation dendron (D1) is represented.

Recently we have described two families of supramolecular liquid crystal dendrimers based on the self-assembly of carbazole-derived dendrons as the electron-donating group and an electron accepting 1,3,5-triazine core. The photoconductivity of these materials was studied. It was concluded that all of the compounds, both dendrons and complexes, exhibited photoconductivity of the same order of magnitude. ${ }^{14}$

To date, hybrid dendrimers consisting of two different dendritic polymeric segments are very scarce. ${ }^{8 d, 15}$ As a continuation of our investigations, the aim of this work is prepare, through ionic bonding, functional ionic hybrid liquid crystal dendrimers to use the mesomorphic properties as a tool to organize these materials and to evaluate the luminescence and electrochemical properties. Two novel families of dendrimers were synthesized from poly(propylene imine) (PPI) dendrimer generations 1 to 5 (bearing 4, 8, 16, 32, $64 \mathrm{NH}_{2}$ terminal groups). The PPI was surrounded by carboxylic acid dendrons of two generations G1 and G2 (in future we will denoted as D1 and D2 in order to avoid a mistake with the generations of PPI $G=1-5$ ) bifunctionalized with promesogenic units (family A derived from 5-[4-(4-butoxybenzoyloxy)phenyloxy]pentanoic acid and family B derived from cholesteryl hemisuccinate) and carbazole groups as peripheral hole-transporting moieties and fluorescent units.

The structure of ionic hybrid dendrimers and dendrons are shown in Scheme 1.

\section{Nomenclature}

Carboxylic acid dendrons used to prepare the dendrimers are denoted as $\mathrm{CzXm}$, where $\mathrm{Cz}$ indicates carbazole unit, $\mathrm{m}$ refers 


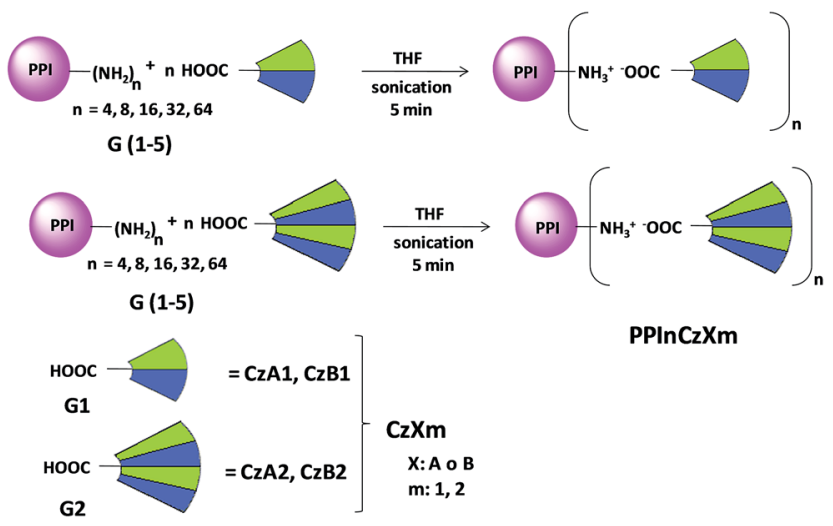

Scheme 2 Synthetic route of ionic hybrid dendrimers derived from PPI dendrimers and bis-(MPA) bifunctionalized dendrons. PPI is represented in pink. In the carboxylic dendrons the carbazole-containing moiety is represented in blue and the mesogenic unit in green.

the generation of dendrons (D1 and D2) and X represent the promesogenic units ( $\mathrm{X}=\mathrm{A}$ : 5-(4-(4-butoxybenzoyloxy)phenyloxy) pentanoic acid and $\mathrm{X}=\mathrm{B}$ : cholesteryl hemisuccinate). The hybrid ionic dendrimers are denoted $\mathrm{PPI}_{n} \mathrm{CzXm}$, where PPI represent the poly(propylene imine) dendrimer core and $n$ refers to the number of amino groups $(n=4,8,16,32,64$, that correspond at $\mathrm{G}=1-5$ respectively).

\section{Experimental}

\section{Synthesis}

Dendritic carboxylic acids. The synthesis of the bifunctionalized dendrons CzXm was described in a previous paper ${ }^{14 a}$ and was carried out according to the method described by Fréchet $e t$ $a l .{ }^{16}$ The reaction involves nucleophilic attack by the carbazolecontaining amine to a cyclic carbonate derived from 2,2-bis(hydroxymethyl)propanoic acid (bis-MPA). This leads to the formation of a carbamate linkage with concomitant generation of a hydroxyl group, which can subsequently be reacted with a carboxylic acid. Thus, two different moieties can be added in immediate succession without any deprotection steps or functional group conversions. The synthetic route is shown in Scheme S1. $\dagger$

Ionic hybrid dendrimers. Ionic hybrid dendrimers were synthesized by a procedure previously described by $\mathrm{us}^{7 c}$ following the method of Crooks ${ }^{17}$ (see Scheme 2).

The corresponding carbazole-containing dendritic carboxylic acid CzXm ( $n$ equiv.) was dissolved in anhydrous tetrahydrofuran (THF). The solution was added to a solution of the corresponding generation (PPI- $\left.\left(\mathrm{NH}_{2}\right)_{n}\right)$ (1 equiv.) in anhydrous THF and the mixture was sonicated for 5 minutes. The solvent was then slowly evaporated at room temperature and the resulting solid was dried in vacuum to constant weight for $c a .12 \mathrm{~h}$ at $40{ }^{\circ} \mathrm{C}$.

\section{Results and discussion}

\section{Characterization of the ionic hybrid dendrimers}

The formation of ionic interactions between the PPI dendrimer and the dendron acids was studied by infrared (IR) spectroscopy and by nuclear magnetic resonance (NMR) in deuterated chloroform solution.

\section{FT-IR characterization}

The main IR data for dendrimers are gathered in Table S1. $\dagger$

It can be seen, as an example, which the carbonyl group region of the dendron two nearly overlapped bands can be observed at 1737 and $1729 \mathrm{~cm}^{-1}$, assigned to the carbonyl groups of the carboxylic acid and ester, respectively. When the ionic pairs are formed, the signal at $1737 \mathrm{~cm}^{-1}$ disappears and two bands at 1576 and $1405 \mathrm{~cm}^{-1}$ corresponding, respectively, to the asymmetric and symmetric stretching modes of the carboxylate groups in the hybrid ionic dendrimer $\mathrm{PPI}_{16} \mathrm{CzB1}$ appeared, whereas the signal at $1728 \mathrm{~cm}^{-1}$ corresponding to the ester remains, (Fig. $\mathrm{S} 1 \dagger$ ).

Changes in the region for $\mathrm{N}-\mathrm{H}$ bonds can also be observed: two bands, corresponding to the $\mathrm{N}-\mathrm{H}$ bonds of the PPI dendrimer core, disappear and are replaced by a broad band between 3600 and $3200 \mathrm{~cm}^{-1}$, corresponding to the protonated amines $\left(\mathrm{NH}^{3+}\right)$ of PPI and the $\mathrm{N}-\mathrm{H}$ bonds of the carbamate groups.

\section{NMR characterization}

The chemical structures of the ionic dendritic polymers were analyzed by one-dimensional ${ }^{1} \mathrm{H}$ and ${ }^{13} \mathrm{C}$ NMR and twodimensional ${ }^{1} \mathrm{H}^{-1}{ }^{1} \mathrm{COSY},{ }^{1} \mathrm{H}^{13}{ }^{13} \mathrm{C}$ HSQC and ${ }^{1} \mathrm{H}^{13}{ }^{13} \mathrm{C} \mathrm{HMBC}$ NMR. The results obtained confirm the formation of the salts and, as representative examples, ${ }^{1} \mathrm{H}$ NMR data for carboxylic acids and the ionic complexes derived from $\mathrm{PPI}_{n} \mathrm{CzXm}$ are collected in Table S2 $\uparrow$ and are shown in Fig. S2. $\dagger$ The total ${ }^{1} \mathrm{H}$ and ${ }^{13} \mathrm{C}$ assignments of dendrons are described in our previous paper. ${ }^{14 a}$ In Fig. S2 and S3 $\uparrow$ we show ${ }^{1} \mathrm{H}$ NMR and ${ }^{13} \mathrm{C}$ NMR spectra of CzB1 and its corresponding dendrimers of the 3rd, 4th and 5th generations were only we indicate the main signals involved in ionic interactions.

The signals corresponding to the protons of the acid groups are very broad and are barely visible in the ${ }^{1} \mathrm{H}$ spectrum. As a consequence, these signals cannot be taken into account to discuss the formation of the salts. The highest chemical shifts in the dendron part are related to the nuclei nearest to the focal point. Thus, the signals for the protons of the diastereotopic methylene $\left(\mathrm{H}_{\mathrm{s}, \mathrm{s}^{\prime}}\right.$, see Fig. $\left.\mathrm{S} 2 \dagger\right)$ and the methyl group $\beta$ to the carboxylic acid group $\left(\mathrm{H}_{\mathrm{u}}\right)$ move to higher field in the carboxylate but the signal due to the proton of the carbamate group $(-\mathrm{OCONH}-)$ is shifted downfield. Protonation of the primary amine groups on the dendrimer surface is confirmed by the downfield shift of the $\mathrm{H}_{\mathrm{B}}$ signal $\alpha$ to the terminal amino group $(\sim 0.3 \mathrm{ppm})$.

${ }^{13} \mathrm{C}$ NMR is more sensitive to this effect than ${ }^{1} \mathrm{H}$ NMR and there are two main pieces of evidence in this respect. Firstly, when the amine is protonated, the signal for the carbon $\alpha$ to $\mathrm{NH}_{2}\left(\mathrm{C}_{\mathrm{B}}\right)$ moves from 40.2/40.6 ppm to $38.6 \mathrm{ppm}$ (data confirmed by an HSQC experiment) and the shifts of the carbon signals belonging to the dendron $\left(\mathrm{C}_{\mathrm{s}, \mathrm{s}^{\prime}}\right)$ move from $65.48 \mathrm{ppm}$ and $65.78 \mathrm{ppm}$ to $66.84 \mathrm{ppm}$ and $67.24 \mathrm{ppm}$, respectively. Moreover, the ${ }^{13} \mathrm{C}$ signal of the carboxylic acid group $\left(\mathrm{C}_{\mathrm{z}}\right)$ is 


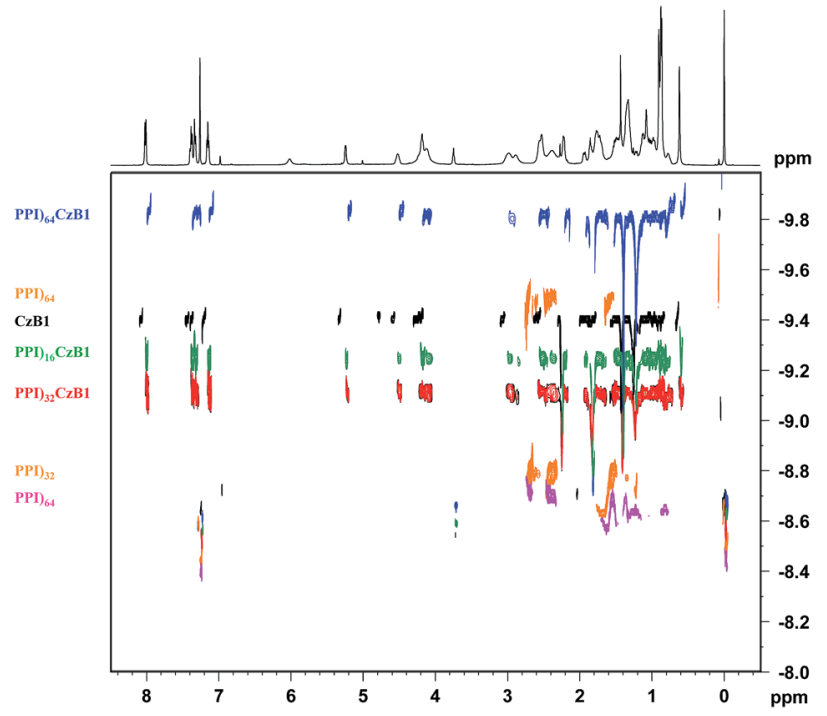

Fig. $1{ }^{1} \mathrm{H}$ DOSY NMR spectra of dendron CzB1, PPI derivatives of the 3rd, 4th and 5th generation and their related ionic dendrimers $\mathrm{PPI}_{16}{ }^{-}$ $\mathrm{C} z \mathrm{~B} 1, \mathrm{PPI}_{32} \mathrm{CzB1}, \mathrm{PPI}_{64} \mathrm{CzB1}\left(500 \mathrm{MHz}, \mathrm{CDCl}_{3}, 25^{\circ} \mathrm{C}\right)$. The projection corresponds to $\mathrm{PPI}_{32} \mathrm{CzB} 1$.

shifted to lower field by between +1 and $+4 \mathrm{ppm}$, the signal for the methylic carbon $\left(\mathrm{C}_{\mathrm{u}}\right) \beta$ to the carboxyl group is shifted to lower field from $17.60 \mathrm{ppm}$ to $18.77 \mathrm{ppm}$ and the ${ }^{13} \mathrm{C}$ signal of the carbamate group $\left(\mathrm{C}_{\mathrm{r}^{\prime}}\right)$ is also deshielded (from $155.89 \mathrm{ppm}$ to $156.81 \mathrm{ppm}$ ) (see Fig. $\mathrm{S} 2 \dagger$ ).

The strength of the ionic interaction in solution was assessed by diffusion NMR (DOSY). These studies were carried out on a dendron (CzB1), on PPI dendrimers and on three of zwitterionic dendrimers corresponding to generations 3,4 and 5 of the PPI dendrimer. Once the diffusion coefficients had been obtained relative to an internal standard ${ }^{\mathbf{1 8}}$ (TMS) it was observed that the ionic dendrimers behave as single molecules in solution, with only a single diffusion coefficient observed (Fig. 1).

This finding confirms that the ionic bond is strong enough to keep the two parts of the ionic dendrimer linked in solution.
In previous studies on different ionic dendrimers ${ }^{7 c, 19}$ our group found that in solution the bond strength was not sufficiently high to keep the two parts together in the ionic dendrimer. There are examples where DOSY studies have been used to estimate the extent of ion-pairing interactions in salts, mainly in transition metal complexes ${ }^{20}$ and a few on dendrimers with cations of medicinal interest. ${ }^{21}$ The latter study confirms the interaction between ionic molecules but these did not diffuse with the same coefficient. In our case, the coefficients are an average between those of the dendron and free PPI, except for the generation 5 complexes which have a much lower coefficient. The relative positions of the anion and the cation were studied by NOESY experiments. It can be seen from Fig. S4† that the protons of the terminal branches dock closely with diastereotopic protons of the carboxylic acid dendron and with the methyl protons (cross-peaks are indicated in Fig. S4†). An NOE effect between functional groups and PPI was not observed.

The signals for the aromatic protons of the dendron become more shielded on increasing the PPI generation, a trend that suggests a more compact arrangement of the dendron around the dendrimer and thus a stronger bond for $\mathrm{PPI}_{64} \mathrm{CzB} 1$, which would explain its different diffusion behavior.

The downfield shift of the carboxylic carbon $\left(\mathrm{C}_{\mathrm{z}}\right)$ signal in ${ }^{13} \mathrm{C}$ CPMAS experiments performed on $\mathrm{CzB} 1$ and $\mathrm{PPI}_{64} \mathrm{CzB} 1$ provides evidence for the formation of the carboxylate anion (Fig. S5†).

\section{Thermal stability of the dendrimers}

The thermal stability of the dendrimers and carboxylic dendrons was studied by thermogravimetric analysis (TGA) under a nitrogen atmosphere (see Table S3†).

\section{Thermogravimetric analysis}

Was used to determine the temperature at which five percent of the initial mass was lost and the onset temperatures for decomposition of these materials, both of which were found to depend on the dendron or on the generation of the dendrimer.

Table 1 Transition temperatures $\left({ }^{\circ} \mathrm{C}\right)$ and mesogenic behavior ${ }^{c}$ of ionic hybrid dendrimers

\begin{tabular}{|c|c|c|c|}
\hline $\begin{array}{l}\text { Ionic hybrid } \\
\text { dendrimer }\end{array}$ & Transition temperature ${ }^{a}\left({ }^{\circ} \mathrm{C}\right)$ & Ionic hybrid dendrimer & Transition temperature ${ }^{a}\left({ }^{\circ} \mathrm{C}\right)$ \\
\hline CzA1 & C 52 I & $\mathrm{CzA} 2$ & $\mathrm{~N}_{\mathrm{g}} 25 \mathrm{~N} 66 \mathrm{I}$ \\
\hline $\mathrm{PPI}_{8} \mathrm{CzA} 1$ & $\mathrm{~N}_{\mathrm{g}} 6 \mathrm{~N} 47 \mathrm{I}$ & $\mathrm{PPI}_{8} \mathrm{CzA} 2$ & $\mathrm{~N}_{\mathrm{g}} 32 \mathrm{~N} 81 \mathrm{I}$ \\
\hline $\mathrm{PPI}_{16} \mathrm{CzA} 1$ & $\mathrm{~N}_{\mathrm{g}} 8 \mathrm{~N} 72 \mathrm{I}$ & $\mathrm{PPI}_{16} \mathrm{CzA} 2$ & $\mathrm{~N}_{\mathrm{g}} 6 \mathrm{~N} 65 \mathrm{I}$ \\
\hline $\mathrm{PPI}_{32} \mathrm{CzA} 1$ & $\mathrm{~N}_{\mathrm{g}} 29 \mathrm{~N} 69 \mathrm{I}$ & $\mathrm{PPI}_{32} \mathrm{CzA} 2$ & $\mathrm{Col}_{\mathrm{rg}} 5 \mathrm{Col}_{\mathrm{r}} 66 \mathrm{I}$ \\
\hline $\mathrm{PPI}_{4} \mathrm{CzB} 1$ & $\mathrm{SmA}_{\mathrm{g}} 50 \mathrm{SmA} 95^{b} \mathrm{I}$ & $\mathrm{PPI}_{4} \mathrm{CzB} 2$ & $\mathrm{SmA}_{\mathrm{g}} 75 \mathrm{SmA} 110 \mathrm{I}$ \\
\hline $\mathrm{PPI}_{8} \mathrm{CzB1}$ & $\mathrm{SmA}_{\mathrm{g}} 42 \mathrm{SmA} 92 \mathrm{I}$ & $\mathrm{PPI}_{8} \mathrm{CzB} 2$ & $\mathrm{SmA}_{\mathrm{g}} 72 \mathrm{SmA} 115 \mathrm{I}$ \\
\hline $\mathrm{PPI}_{16} \mathrm{CzB} 1$ & $\mathrm{SmA}_{\mathrm{g}}-11 \mathrm{SmA} 100$ & $\mathrm{PPI}_{16} \mathrm{CzB} 2$ & $\mathrm{SmA}_{\mathrm{g}} 42 \mathrm{SmA} 89 \mathrm{I}$ \\
\hline $\mathrm{PPI}_{32} \mathrm{CzB} 1$ & $\mathrm{SmA}_{\mathrm{g}} 35 \mathrm{SmA} 124^{b}$ & $\mathrm{PPI}_{32} \mathrm{CzB} 2$ & $\mathrm{SmA}_{\mathrm{g}}^{3} 33 \mathrm{SmA} 90 \mathrm{I}$ \\
\hline $\mathrm{PPI}_{64} \mathrm{CzB1}$ & $\mathrm{Col}_{\mathrm{rg}}^{\mathrm{s}} 37 \mathrm{Col}_{\mathrm{r}} 117 \mathrm{I}$ & $\mathrm{PPI}_{64} \mathrm{CzB} 2$ & $\mathrm{Col}_{\mathrm{hg}} 35 \mathrm{Col}_{\mathrm{h}} 92 \mathrm{I}$ \\
\hline
\end{tabular}

${ }^{a}$ Transition data obtained by DSC corresponding to the second heating process performed at $10^{\circ} \mathrm{C} \mathrm{min}^{-1} \cdot{ }^{b} \mathrm{Optical}$ data. ${ }^{c} \mathrm{C}=\mathrm{crystalline} \mathrm{phase,} \mathrm{N}$ :

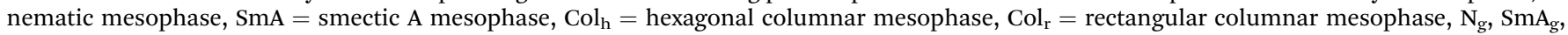
$\mathrm{Col}_{\mathrm{rg}}, \mathrm{Col}_{\mathrm{hg}}$ : glassy phases, $\mathrm{I}=$ isotropic liquid. 
The study of the thermal stability of the dendrons ${ }^{14 a}$ and dendrimers indicated that the materials have good stability and in all cases the $5 \%$ weight loss are observed above the clearing point.

\section{Liquid crystalline properties}

The mesomorphic behavior of the compounds was analyzed by POM, DSC and X-ray diffraction. Three cycles were carried out in DSC experiments and data were taken from the second cycle. The DSC thermograms of these dendrimers were reproducible after the second and subsequent heating-cooling cycles. In some cases, the isotropization temperatures were taken from POM observations because transition peaks were not detected in DSC curves. ${ }^{\mathbf{1 4}}$ The transition temperatures are listed in Table 1. The identification of the liquid crystal phase was carried out on the basis of POM observations and was confirmed by X-ray diffraction. Of the dendrons, only CzA2 exhibits mesomorphic properties, ${ }^{\mathbf{1 4 a}}$ on the other hand, all dendrimers synthesized were liquid crystalline. Dendrimers derived from dendrons CzA1 exhibit a nematic phase for generations 1 to 4 of PPI. The nematic phase was identified by optical microscopy on applying mechanical stress to the sample showing a birefringent texture and was confirmed by X-ray diffraction, however the ionic hybrid dendrimer $\mathrm{PPI}_{64} \mathrm{CzA} 1$ surrounded by 64 CzA1 (D1) dendrons exhibit a rectangular columnar mesophase. Dendrimers decorated with the dendron CzA2 (D2) exhibit a nematic phase for generations 1 to 3 , however a rectangular columnar phase appears for generation 4 (32 terminal groups) of PPI dendrimer and a columnar hexagonal phase is observed for PPI G $=5$ (64 terminal groups).

Dendrimers derived from dendrons CzBm show a smectic A mesophase for PPI generations $\mathrm{G}=1-4$ and columnar phases for $\mathrm{G}=5$. The smectic A and columnar nature of the mesophases was confirmed by X-ray diffraction. Changes in the texture or DSC peaks were not observed upon cooling the samples, indicating that the mesophase freezes into a glassy state that retains the liquid crystal structure. This situation was confirmed by X-ray diffraction of this glassy state. The POM textures in the SmA phase and DSC scans of two ionic hybrid dendrimers ( $\mathrm{PPI}_{4} \mathrm{CzB} 1$ and $\mathrm{PPI}_{32} \mathrm{CzB} 1$ ) are shown in Fig. 2 as examples. DSC scan for ionic hybrid dendrimers $\mathrm{PPI}_{16} \mathrm{CzA} 1$, $\mathrm{PPI}_{16} \mathrm{~B} 1$ are shown in Fig. S6. $\dagger$

\section{$X$-ray studies of the dendrimers}

$\mathrm{X}$-ray experiments were carried out on unoriented samples, in some cases at high temperatures but mostly at room temperature after thermal treatment that involved heating the sample to the isotropic liquid and then cooling it down to room temperature. Under these conditions the compounds investigated were in the liquid crystalline state, with the exception of dendrons CzA1, CzB1 and CzB2, which are not mesomorphic.

For the nematic mesophases the absence of Bragg reflections helped to confirm the absence of periodic positional order. The X-ray patterns contain a diffuse maximum in the low-angle region, which is characteristic of the local correlations along the long axis of the molecules, and a broad, diffuse halo in the
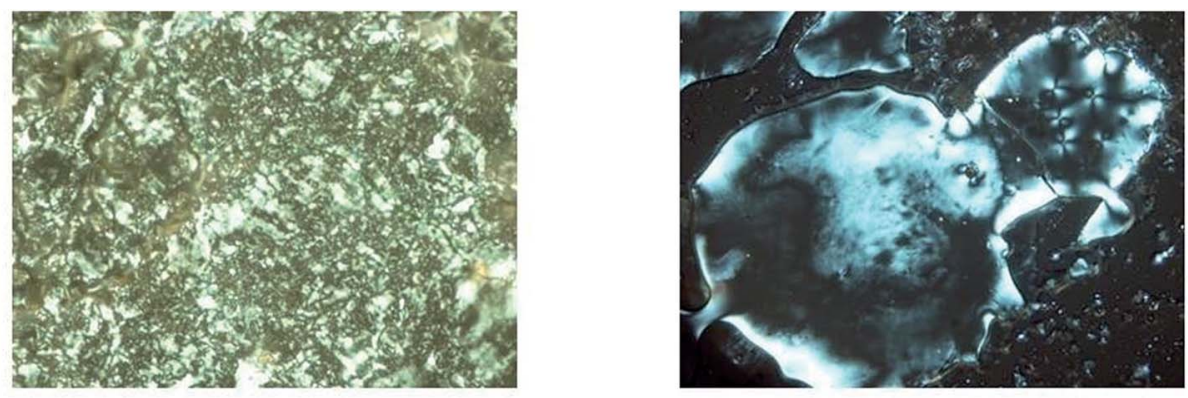

a)

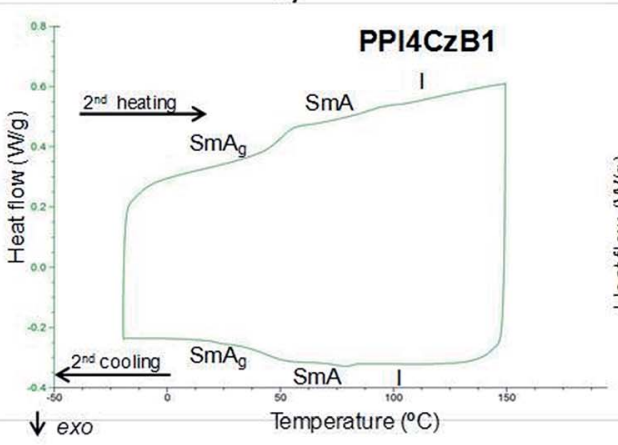

c) b)

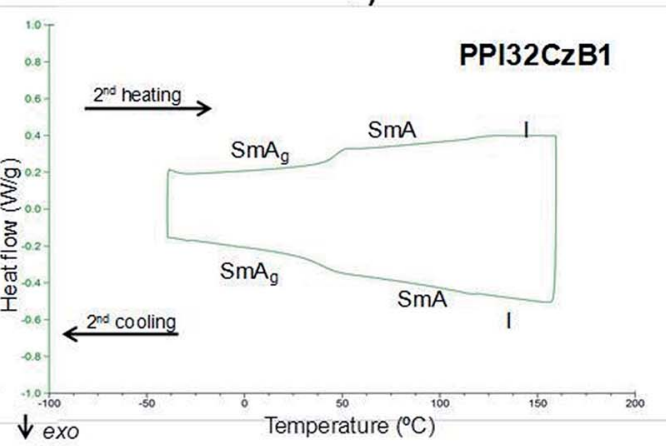

d)

Fig. 2 (a) POM texture of $\mathrm{PPI}_{4} \mathrm{CzB} 1$ in the glassy SmA phase $(\times 10)$. (b) POM texture of $\mathrm{PPI}_{32} \mathrm{CzB} 1$ at $94{ }^{\circ} \mathrm{C}$ in the second heating process in the SmA phase, ( $\times 20)$. (c) DSC scan at $10{ }^{\circ} \mathrm{C}$ min $^{-1}$ for ionic hybrid dendrimer $\mathrm{PPI}_{4} \mathrm{CzB1}$. (d) DSC scans at $10^{\circ} \mathrm{C}$ min ${ }^{-1}$ for ionic hybrid dendrimer $\mathrm{PPI}_{32} \mathrm{CzB} 1$ 

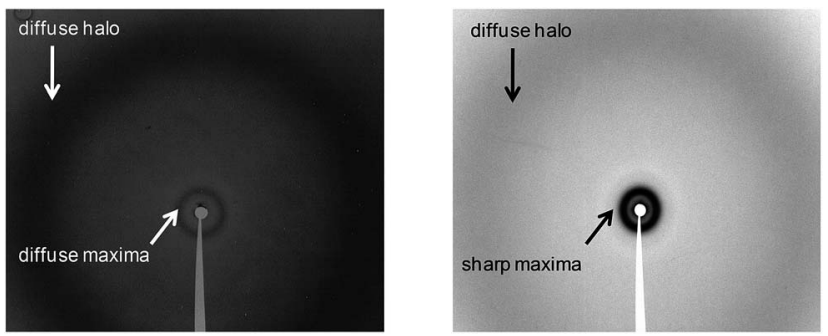

Fig. 3 Room-temperature $\mathrm{X}$-ray patterns of (a) dendrimer $\mathrm{PPI}_{8} \mathrm{CzA} 1$ in the $\mathrm{N}$ mesophase, (b) dendrimer $\mathrm{PPI}_{16} \mathrm{CzB} 1$ in the $\mathrm{SmA}$ mesophase.

high-angle region, which is typical of the conformational disorder of the aliphatic chains and is related to the local lateral interferences (Fig. 3a).

The lamellar positional order inherent in the smectic mesophases produced Bragg spots that were characteristic of the layer spacing. Consequently, in addition to the high-angle broad halo related to the conformational disorder and to the short-range correlations in the layer plane, the X-ray patterns of the smectic mesophases in this series contain one or more sharp reflections in the low-angle region, corresponding to the arrangement of the molecules in regularly spaced parallel layers. The presence of several low-angle maxima in the reciprocal spacing ratio 1:2:3 etc. is related to the successive reflection orders. However, the presence of a single maximum provided sufficient evidence to assign a smectic mesophase (Fig. 3b). The deduced spacings for all of the smectic mesophases are listed in Table 2.

The data obtained are consistent with the adoption by the molecules of a cylinder-shaped conformation. In this cylinder, in a similar way to the model described for other smectic liquid crystalline dendrimers, ${ }^{6 a, 6 c, 7 c}$ the central region is occupied by the PPI core, with the ionic pairs pointing upwards and downwards, and the dendrons are statistically distributed at both ends (Fig. 4, top left). In fact, this model is valid for both the nematic and the smectic mesophases. However, in the nematic mesophase there is only orientational order and there is no positional periodicity, whereas in the smectic mesophase there is a regular arrangement in layers in addition to the orientational order (Fig. 4, bottom left).
In an effort to gain an insight into the molecular arrangement and the packing in the mesophase, calculations can be carried out on the assumption that the density of the organic molecules is close to $1 \mathrm{~g} \mathrm{~cm}^{-3}$. Assuming that the functionalization of the terminal amino groups of PPI is complete, it is possible to estimate the diameter $\Phi$ in $\AA$ of the cylindrical molecules and, from this value, the cross-section Sd in $\AA^{2}$ of each dendron considered perpendicular to the cylinder axis (see ESI $\dagger$ and Fig. 4, top left).

The structural parameters, the diameter of the cylindrical molecule $(\Phi)$ and the cross-section of each dendron (Sd) in the smectic (SmA) mesophase are listed in Table 2. These data show that the cylinder height ( $d$, layer spacing) does not change appreciably on varying the generation of the dendrimer or of the dendron. This trend is in reasonable agreement with the results found for other smectic liquid crystalline dendrimers and is due to the predominant spreading of the dendritic branches of PPI in the plane perpendicular to the cylinder axis, a situation that arises in order to accommodate all the dendrons. Furthermore, it is observed that the surface required by the second-generation dendrons ( $145 \AA^{2}$ on average) is approximately twice the surface required by the first-generation dendrons ( $74 \AA^{2}$ on average), which is consistent with the proposed cylindrical arrangement. Moreover, as mentioned below, the occurrence of columnar mesomorphism for a lower generation of PPI in the case of the second-generation dendron can be accounted for by its higher space requirements, which force the dendrimers to change their conformation from cylindrical to disc-like for a lower generation.

The evolution from smectic to columnar mesomorphism is related to this conformational change. Indeed, in the case of dendron CzB1 it can be observed that the molecule diameter $\Phi$ increases with the PPI generation (Table 2) until a situation is reached where the molecule adopts the shape of a flattened cylinder, the diameter of which is almost equal to its height (PPI ${ }_{32} \mathrm{CzB1}$ ). For a higher PPI generation a situation is reached in which the cylinder cross-section does not have enough space to accommodate the increasingly large number of dendrons. At this point, a dramatic conformational change takes place and the dendrons arrange themselves around the PPI core because the steric hindrance encountered in the cylindrical arrangement is relieved if the dendrons shift to a radial orientation, thus yielding a disc shape (Fig. 4, top right).

Table 2 X-ray structural parameters $(\AA)$ for the smectic mesophases

\begin{tabular}{llllll}
\hline Ionic hybrid dendrimer & Mesophase $^{a}$ & Temperature $^{b}\left({ }^{\circ} \mathrm{C}\right)$ & Parameters $(\AA)$ & $\Phi(\AA)($ calculate $)$ & $S_{\text {d }}\left(\AA^{2}\right)($ calculate $)$ \\
\hline PPI $_{4}$ CzB1 & SmA & 50 & $d=42.5$ & 13.8 & 75.1 \\
PPI $_{8}$ CzB1 & SmA & 42 & $d=42.5$ & 19.7 & 76.4 \\
PPI $_{16}$ CzB1 & SmA & rt & $d=46.6$ & 27 & 71.3 \\
PPI $_{32}$ CzB1 & SmA & rt & $d=45.4$ & 38.7 & 13.5 \\
PPI $_{4}$ CzB2 & SmA & rt & $d=44.8$ & 26.1 & 143.8 \\
PPI $_{8}$ CzB2 & SmA & rt & $d=47.4$ & 39.8 & 137.2 \\
PPI $_{16}$ CzB2 & SmA & rt & $d=45.2$ & 54.7 & 146.9
\end{tabular}

${ }^{a} \mathrm{SmA}=$ smectic A mesophase. ${ }^{b} \mathrm{rt}=$ room temperature. 

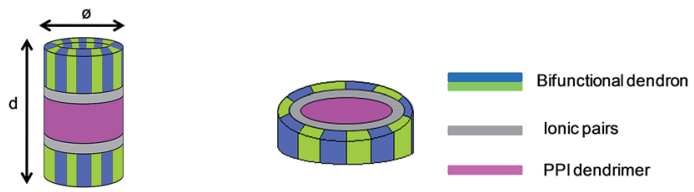
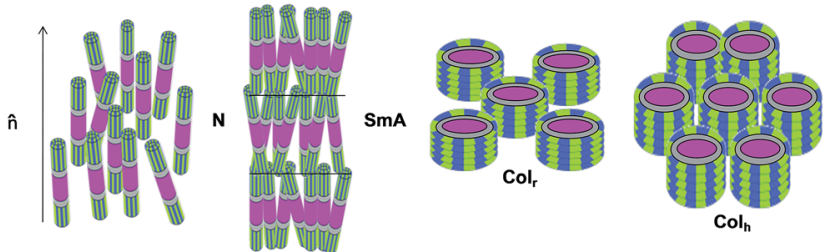

Fig. 4 Proposed arrangement of the dendrimers in the nematic, smectic A and columnar mesophases. $d$ : layer thickness, $\Phi$ : cylinder diameter; values are gathered in Table 1.

When this disc-like arrangement is achieved, the molecules stack in columns and these columns pack in a two-dimensional lattice with rectangular symmetry for $\mathrm{PPI}_{64} \mathrm{CzA} 1, \mathrm{PPI}_{64} \mathrm{CzB} 1$ and $\mathrm{PPI}_{32}$ CzA2 (Fig. 4, bottom right). Columnar mesophases yield Xray diffraction patterns that contain a set of sharp maxima in the low-angle region, which are characteristic of the twodimensional packing of columns, and a broad, diffuse halo at high angles, which is typical of the conformational disorder of the aliphatic chains and is consistent with the absence of a regular stacking distance along the column axis. The measured spacing and the deduced structural parameters are given in Table 3 . The rectangular symmetry of the columnar packing for these three compounds is deduced from the presence of two low-angle sharp maxima that can be assigned, respectively, to the (1 1 1) and ( $\left.\begin{array}{ll}0 & 2\end{array}\right)$ reflections of the two-dimensional rectangular lattice, from which the lattice constants $a$ and $b$ are obtained.

When the highest PPI generation is ionically bonded to second-generation dendrons (compounds $\mathrm{PPI}_{64} \mathrm{CzA} 2$ and $\mathrm{PPI}_{64} \mathrm{CzB} 2$ ), the mutual balance between the distinct regions of the molecule produces a different spatial arrangement and a hexagonal symmetry is generated (Fig. 4, bottom right). The hexagonal symmetry is deduced from the presence of two low- angle sharp maxima in the reciprocal spacing ratio $1: \sqrt{ } 3$, which are assigned, respectively, to the (1 0 ) and (1 1 1) reflections of the two-dimensional hexagonal lattice, from which the lattice constant a is obtained. As for the rectangular columnar mesophases in this series, only a broad, diffuse halo is observed in the high-angle region. As for the smectic mesophases, simple calculations can be carried out for the columnar mesophases in order to gain an insight into the packing in the liquid crystal phase. These calculations enable values for $h_{\mathrm{d}}$ to be estimated (Table 3; see ESI $\dagger$ ). This parameter is the mean disc thickness or, expressed otherwise, the height of column required to accommodate one molecule. Comparison of the $h_{\mathrm{d}}$ values with the lattice constants gathered in Table 3 indicates that these molecules in the columnar mesophases have a considerable thickness compared to their cross-section and, therefore, their shape is more appropriately described as cylindrical than disclike. Another significant conclusion drawn from the $h_{\mathrm{d}}$ values gathered in Table 3 is related to their evolution upon changing the PPI generation. On considering dendron CzA2, the only one that is present in the two hybrid dendrimers collected in Table 3 ( $\mathrm{PPI}_{32} \mathrm{CzA} 2$ and $\mathrm{PPI}_{64} \mathrm{CzA} 2$ ), the difference in $h_{\mathrm{d}}$ on increasing the PPI generation from 4 to 5 is $11 \AA$. This is consistent with the data reported in the literature for similar situations and is accounted for by a preferential elongation of the PPI branches in the direction of the column axis. ${ }^{22}$

\section{Optical properties}

The UV-vis absorption and emission spectra of the hybrid dendrimers were recorded in dichloromethane solution $\left(10^{-5}\right.$ $\mathrm{M}$ for absorption and $10^{-7} \mathrm{M}$ for emission) and also on films cast at room temperature. The data are summarized in Tables S4 and S5. $\uparrow$ Only data for hybrid dendrimers of PPI G $=1$ and dendrons D1 (CzA1, CzB1) are discussed because the other generations exhibit a similar behavior.

In the UV region all of the hybrid dendrimers present absorption bands at $265 \mathrm{~nm}, 295 \mathrm{~nm}$ and $332 \mathrm{~nm}$, which are assigned to carbazole-centered transitions, $\pi-\pi^{*}$ transitions and $n-\pi^{*}$ transitions, respectively. The emission spectra (excitation at $295 \mathrm{~nm}$ ) all exhibit two bands at $352 \mathrm{~nm}$ and $369 \mathrm{~nm}$ along with a shoulder at $388 \mathrm{~nm}$.

Table 3 X-ray structural parameters (Å) for the columnar mesophases

\begin{tabular}{|c|c|c|c|c|c|c|c|}
\hline Ionic hybrid dendrimer & Mesophase & $T\left({ }^{\circ} \mathrm{C}\right)$ & Parameters $(\AA)$ & $d_{\text {obs }}(\AA)$ & $d_{\text {calc }}(\AA)$ & $h_{\mathrm{d}}^{b}(\AA)$ & $h_{\mathrm{k}}$ \\
\hline \multirow{2}{*}{$\mathrm{PPI}_{64} \mathrm{CzA} 1$} & \multirow[t]{2}{*}{$\mathrm{Col}_{\mathrm{r}}$} & \multirow[t]{2}{*}{$\mathrm{rt}$} & $a=69.3$ & 42.3 & 42.3 & \multirow[t]{2}{*}{51.3} & 11 \\
\hline & & & $b=53.4$ & 26.7 & 26.7 & & 02 \\
\hline $\mathrm{PPI}_{64} \mathrm{CzB} 1$ & $\mathrm{Col}_{\mathrm{r}}$ & $37^{a}$ & $b=58$ & 28.8 & 29 & 49.8 & 02 \\
\hline \multirow[t]{2}{*}{$\mathrm{PPI}_{32} \mathrm{CzA} 2$} & \multirow[t]{2}{*}{$\mathrm{Col}_{\mathrm{r}}$} & \multirow[t]{2}{*}{$\mathrm{rt}$} & $a=62.8$ & 39.4 & 38.9 & \multirow[t]{2}{*}{59.2} & 11 \\
\hline & & & $b=50.6$ & 25.3 & 25.1 & & 02 \\
\hline \multirow[t]{2}{*}{$\mathrm{PPI}_{64} \mathrm{CzB} 2$} & \multirow[t]{2}{*}{$\mathrm{Col}_{\mathrm{h}}$} & \multirow[t]{2}{*}{$\mathrm{rt}$} & \multirow[t]{2}{*}{$a=55.9$} & 48.8 & 48.4 & \multirow[t]{2}{*}{88.1} & 10 \\
\hline & & & & 27.6 & 27.9 & & 11 \\
\hline
\end{tabular}

${ }^{a}$ Data obtained at $37^{\circ} \mathrm{C}$ in the heating process. ${ }^{b}$ Disc thickness $\left(h_{\mathrm{d}}=10 \times \mathrm{M} /(6.023 \times a \times(b / 2))\right.$ for the $\mathrm{Col}_{\mathrm{r}}$ phase and $h_{\mathrm{d}}=10 \times \mathrm{M} /(6.023 \times(\sqrt{ } 3 / 2)$ $\times a 2$ ) for the $\mathrm{Col}_{\mathrm{h}}$ phase). rt: room temperature. $\mathrm{Col}_{\mathrm{r}}$ : rectangular columnar mesophase, $\mathrm{Col}_{\mathrm{h}}$ : hexagonal columnar mesophase. 


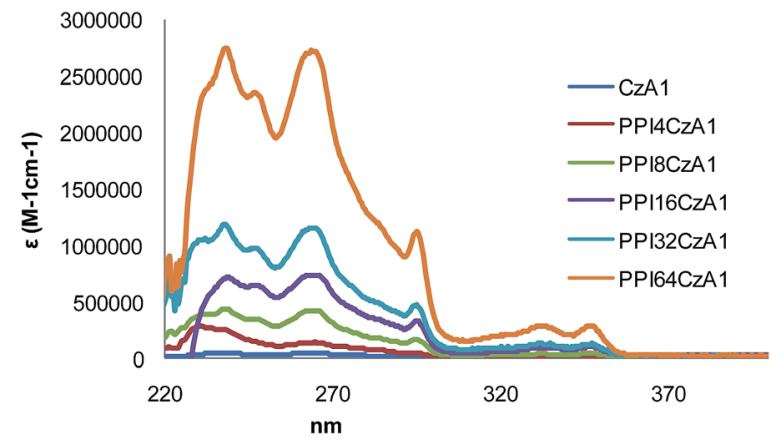

Fig. 5 Normalized UV-vis absorption spectra in $\mathrm{CH}_{2} \mathrm{Cl}_{2}$ solution of dendron $\mathrm{CzA} 1$ and the dendrimers $\mathrm{PPI}_{n} \mathrm{CzA} 1$.

The absorption spectra of dendron CzA1 and the corresponding ionic hybrid dendrimers are shown in Fig. 5. As can be observed, the molar absorbance of the peaks increases in a linear manner with the number of carbazole rings in the dendrimer (related to the generation of the dendrimer PPI, series A).

Comparison of the molar absorbance value for each dendrimer at $265 \mathrm{~nm}$ with the value obtained for the dendron confirms the situation outlined above. The relevant data are collected in Tables S6 and S7.† On the other hand, it was observed that dendrimers $\mathrm{PPI}_{n} \mathrm{CzB} 1$ show a slight deviation from linearity in this behavior. Quantum yields for the $\mathrm{PPI}_{n^{-}}$ CzB1 family were measured with quinine sulfate monohydrate as a standard ( $\Phi=0.546$ in $1 \mathrm{~N} \mathrm{H}_{2} \mathrm{SO}_{4}$ ). The values lie in the range $0.09-0.10$ and the lowest quantum yield was observed for the first generation hybrid ionic dendrimer $(n=4) \mathrm{PPI}_{4} \mathrm{~B} 1$ (data are gathered in Table S8 $\dagger$ ).

The emission of the dendrimers was studied and it was found that the peak maxima are similar in both series derived from dendrons A and B [around 352, 369, 388 (sh) in solution and 355, 372, 389 (sh) in film].

The bands in the emission spectra in mesophase appear broader than the corresponding emission bands in the in solution (Fig. 6). This difference is more noticeable for dendrimers of family A, probably due to the greater ability of the dendrimers of series PPI $_{n}$ CzAm to engage in $\pi-\pi$ interactions between the aromatic rings of the promesogenic unit and the carbazole groups when compared to those of series B. This effect gives rise to a more marked red-shift for the compounds derived from CzAm dendrons. The absorption spectra of dendrons and ionic hybrid dendrimers $\mathrm{PPI}_{n} \mathrm{CzA} 1$ and $\mathrm{PPI}_{n} \mathrm{CzB} 1$ are shown in ESI (Fig. S7†).

\section{Electrochemical properties}

The electrochemical behavior of the ionic hybrid dendrimers was investigated by cyclic voltammetry (CV) and the results are summarized in Table S9. $\dagger$

The potential was cycled between 0 and $2 \mathrm{~V}$ at a scan rate of $100 \mathrm{mV}^{-1}$ against an $\mathrm{Ag} / \mathrm{AgCl}$ reference electrode with a platinum auxiliary electrode and a graphite working electrode. In the first cycle of the CV scan the anodic peaks of the dendrimer are more intense than the cathodic peaks. This marked
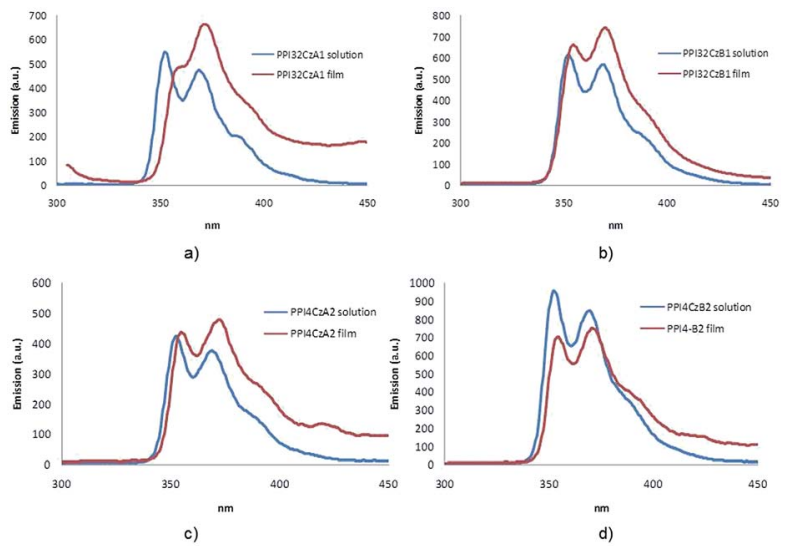

Fig. 6 Emission spectra in $\mathrm{CH}_{2} \mathrm{Cl}_{2}$ solution and in the mesophase film of (a) $\mathrm{PPI}_{32} \mathrm{CzA1}$, (b) $\mathrm{PPI}_{32} \mathrm{CzB} 1$, (c) $\mathrm{PPI}_{4} \mathrm{CzA}$, (d) $\mathrm{PPI}_{4} \mathrm{CzB} 2$.

asymmetry in the redox couple indicates that these species undergo irreversible oxidation.

The dendrimers were studied in five cycles and representative CV curves are shown in Fig. 7 and S8. $\dagger$

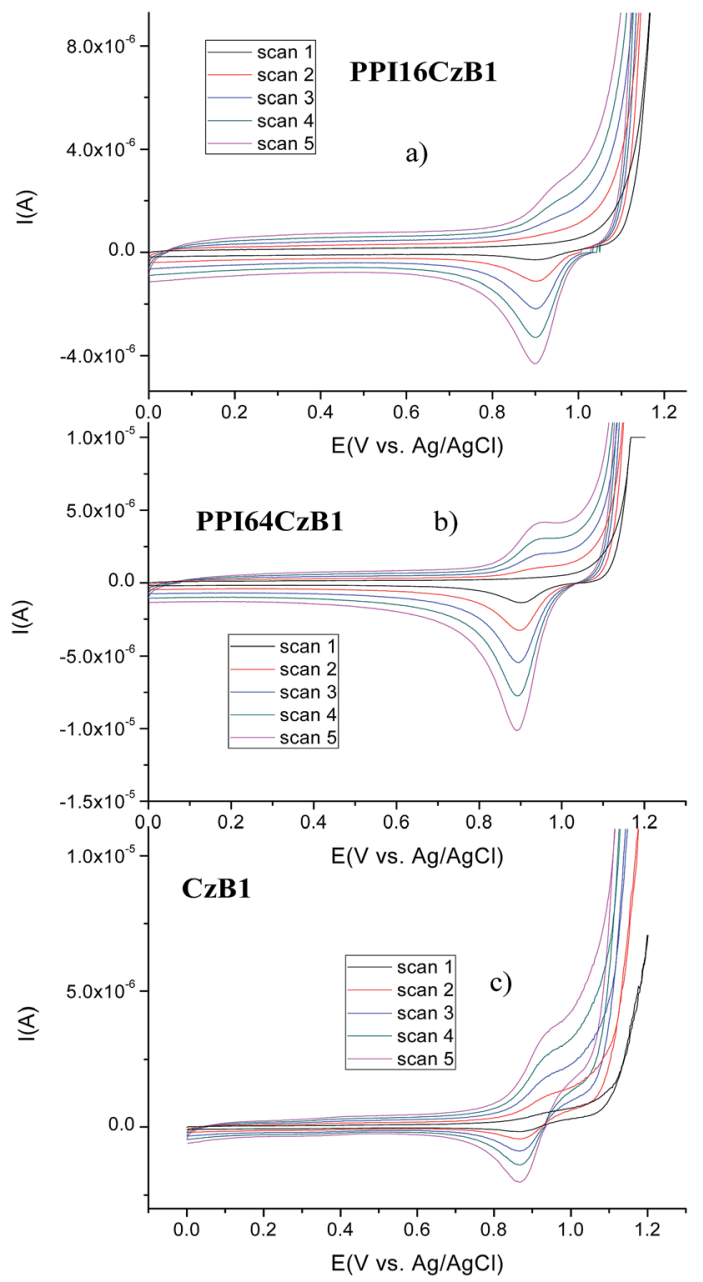

Fig. 7 Cyclic voltammograms of the first five cycles of: (a) $\mathrm{PPI}_{16} \mathrm{CzB1}$, (b) $\mathrm{PPI}_{64} \mathrm{CzB1}$, (c) $\mathrm{CzB1}$. 
Cyclic voltammetry traces obtained using ITO as the working electrode and with the potential cycled between 0 and $2 \mathrm{~V}$ were also studied in order to assess whether electropolymerizaton of the samples occurred (Fig. 7).

It can be observed that the intensity of the oxidation peak increases in successive cycles but the intensity of the reduction peak increases to a lesser extent. In addition, the formation of an electrodeposited film of the ionic hybrid dendrimers takes place on the ITO working electrode. This effect was not observed with the dendrons.

\section{Conclusions}

A new polymeric liquid crystal architecture (ionic hybrid liquid crystalline dendrimers) has been designed and synthetized by complexation between a dendrimer template derived from PPI$\left(\mathrm{NH}_{2}\right)_{n}$ and an electron-donating carbazole dendron shell. The systems are constructed by the formation of ion pairs between the carboxylic acid group of the dendron and the terminal amine groups of the dendrimer.

All of the dendrimers are mesogenic and the mesophase type depends on the generation of dendrimer and the dendron type. Dendrimers derived from CzAm dendrons show nematic and columnar mesomorphism, whereas dendrimers derived from CzBm dendrons exhibit smectic A and columnar mesophases.

All of the systems are luminescent at room temperature in solution and in films, and the intensity of the emission and absorption depends on the number of carbazole units in the dendrimer.

All compounds have electrochemical properties due to presence of carbazole rings, but it was observed that the oxidation behaviour does not depend on the dendrimer generation.

\section{Acknowledgements}

This work was supported by MINECO Spain, under Project CTQ2012-35692 and FEDER funding, EU, and by the Gobierno de Aragón (Research Group E04). S.C. thanks the MICINN (Spain) for an FPI grant. The authors also acknowledge the Microscopy Service of the Universidad de Zaragoza, and Nuclear Magnetic Resonance, Mass Spectrometry, Elemental Analysis and Thermal Analysis Services of CEQMA, Universidad de Zaragoza-CSIC (Spain).

\section{Notes and references}

1 (a) J. M. J. Fréchet and D. A. Tomalia, Dendrimers and Other Dendritic Polymers, Wiley, Hoboken, 2001; (b) D. A. Tomalia, J. B. Christensen and U. Boas, Dendrimers, Dendrons, and Dendritic Polymers: Discovery, Applications, and the Future, Cambridge University Press, New York, NY, 2012.

2 (a) G. R. Newkome, C. N. Moorefield and F. Vögtle, Dendrimers and Dendrons: Concepts, Syntheses, Applications, Wiley-VCH, Weinheim, 2001; (b) S. El Kazzouli, S. Mignani,
M. Bousminaab and J.-P. Majoral, New J. Chem., 2012, 36, 227-240.

3 F. Vogtle, G. Richardt and N. Werner, Dendrimer Chemistry, Wiley-VCH, Weinheim, 2009.

4 D. Astruc, E. Boisselier and C. Ornelas, Chem. Rev., 2010, 110, 1857-1959.

5 S. Hernández-Aínsa, M. Marcos and J. L. Serrano, Dendrimeric and Hyperbranched Liquid Crystal Structures, Handbook of Liquid Crystals: 8 Volume Set, ed. J. W. Goodby, P. J. Collings, T. Kato, C. Tschierske, H. Gleeson and P. Raynes, Wiley-VCH Verlag GmbH \& Co. KGaA, 2nd edn, 2014, vol. 8, pp. 259-300.

6 (a) M. W. P. L. Baars, S. H. M. Söntjens, H. M. Fischer, H. W. I. Peerlings and E. W. Meijer, Chem.-Eur. J., 1998, 4, 2456-2466; (b) J. Barberá, M. Marcos and J. L. Serrano, Chem.-Eur. J., 1999, 5, 1834-1840; (c) S. A. Ponomarenko, N. I. Boiko and V. P. Shibaev, Polym. Sci., Ser. C, 2001, 43, 1-45; (d) B. Donnio and D. Guillon, Adv. Polym. Sci., 2006, 201, 45-155; (e) J. L. Serrano, M. Marcos, R. Martín, M. González and J. Barberá, Chem. Mater., 2003, 15, 38663872; $(f)$ M. Marcos, R. Martín-Rapún, A. Omenat and J. L. Serrano, Chem. Soc. Rev., 2007, 36, 1889-1901; $(g)$ B. M. Rosen, C. J. Wilson, D. A. Wilson, M. Peterca, M. R. Imam and V. Percec, Chem. Rev., 2009, 109, 62756540; (h) C. Tschierske, Angew. Chem., Int. Ed., 2013, 52, 8828-8878.

7 (a) K. V. Axenov and S. Laschat, Materials, 2011, 4, 206-259; (b) A. G. Cook, U. Baumeister and C. Tschierske, J. Mater. Chem., 2005, 15, 1708-1721; (c) R. Martín-Rapún, M. Marcos, A. Omenat, J. Barberá, P. Romero and J. L. Serrano, J. Am. Chem. Soc., 2005, 127, 7397-7403; (d) A. Rapakousiou, Y. Wang, F. Nzulu, R. Djeda, N. Pinaud, J. Ruiz and D. Astruc, Organometallics, 2013, 32, 6079-6090. 8 (a) M. Belloni, B. M. Kariuki, M. Manickam, J. Wilkie and J. A. Preece, Cryst. Growth Des., 2005, 5, 1443-1450; (b) J. V. Grazulevicius, P. Strohriegl, J. Pielichowski and K. Pielichowski, Prog. Polym. Sci., 2003, 28, 1297-1353; (c) V. Percec, M. Glodde, T. K. Bera, Y. Miura, I. Shiyanovskaya, K. D. Singer, V. S. K. Balagurusamy, P. A. Heiney, I. Schnell, A. Rapp, H. W. Spiess, S. D. Hudson and H. Duan, Nature, 2002, 417, 384-387; (d) C. Kaewtong, G. Jiang, M. J. Felipe, B. Pulpoka and R. Advincula, ACS Nano, 2008, 2, 1533-1542; (e) H.-J. Son, W.-S. Han, K. H. Lee, H. J. Jung, C. Lee, J. Ko and S. O. Kang, Chem. Mater., 2006, 18, 5811-5813.

9 (a) Y. Zhang, Y. Cui and P. N. Prasad, Phys. Rev. B: Condens. Matter Mater. Phys., 1992, 46, 9900-9902; (b) K. Albrecht, Y. Kasai, A. Kimoto and K. Yamamoto, Macromolecules, 2008, 41, 3793-3800; (c) S. Fukuma, K. Irie, T. Ikegami, S. Masuo, S. Machida, N. Tanaka and A. Itaya, J. Photochem. Photobiol., A, 2007, 189, 55-64; (d) H. Li, R. Termine, N. Godbert, L. Angiolini, L. Giorgini and A. Golemme, Org. Electron., 2011, 12, 1184-1191; (e) J. Li and A. C. Grimsdale, Chem. Soc. Rev., 2010, 39, 2399-2410; (f) W. Jiang, L. Duan, J. Qiao, G. Dong, D. Zhang, Li. Wang and Y. Qiu, J. Mater. Chem., 2011, 21, 4918-4926; $(g)$ S. Köber, M. Salvador and K. Meerholz, Adv. Mater., 2011, 
23, 4725-4763; (h) D. Sun, Q. Fu, Z. Ren, W. Li, H. Li, D. Mab and S. Yan, J. Mater. Chem. C, 2013, 1, 5344-5350; (i) D. Sun, Q. Fu, Z. Ren, H. Li, a D. Mab and S. Yan, Polym. Chem., 2014, 5, 220-226.

10 M. Manickam, M. Belloni, S. Kumar, S. K. Varshney, D. S. Shankar Rao, P. R. Ashton, J. A. Preece and N. Spencer, J. Mater. Chem., 2001, 11, 2790-2800.

11 E. Perea, F. López-Calahorra and D. Velasco, Liq. Cryst., 2002, 29, 421-428.

12 (a) W. Bao, M. Reddy Billa, K. Kassireddy, M. Haro, M. J. Kelly, S. P. Kitney, M. S. Al Kalifah, P. Wei, D. Dong, M. O'Neill and S. M. Kelly, Liq. Cryst., 2010, 37, 1289-1303; (b) M. Manickam, P. Iqbal, M. Belloni, S. Kumar and J. A. Preece, Isr. J. Chem., 2012, 52, 917-934.

13 M. Manickam, P. Iqbal, M. Belloni, S. Kumar and J. A. Preece, Isr. J. Chem., 2012, 52, 917-934 and references therein.

14 (a) S. Castelar, J. Barberá, M. Marcos, P. Romero, J.-L. Serrano, A. Golemme and R. Termine, J. Mater. Chem. $C$, 2013, 1, 7321-7332; (b) I. Gracia, B. Feringán, J. L. Serrano, R. Termine, A. Golemme, A. Omenat and J. Barberá, Chem.-Eur. J., 2015, 21, 1359-1369; (c) J. Wolska, J. Mieczkowski, D. Pociecha, S. Buathong, B. Donnio, D. Guillon and E. Gorecka, Macromolecules, 2009, 42, 6375-6384.

15 (a) J. Guerra, A. C. Rodrigo, S. Merino, J. Tejeda, J. C. GarcíaMartínez, P. Sánchez-Verdú, V. Ceña and J. Rodríguez-López,
Macromolecules, 2013, 46, 7316-7324; (b) Y. Liu, Y. Fan, X.-Y. Liu, S.-Z. Jiang, Y. Yuan, Y. Chen, F. Cheng and S.-C. Jiang, Soft Matter, 2012, 8, 8361-8369; (c) V. Percec, J. G. Rudick, M. Peterca, M. E. Yurchenko, J. Smidrkal and P. A. Heiney, Chem.-Eur. J., 2008, 14, 3355-3362.

16 A. P. Goodwin, S. S. Lam and J. M. J. Fréchet, J. Am. Chem. Soc., 2007, 129, 6994-6995.

17 V. Chechik, M. Q. Zhao and R. M. Crooks, J. Am. Chem. Soc., 1999, 121, 4910-4911.

18 E. J. Cabrita and S. Berger, Magn. Reson. Chem., 2001, 39, S142-S148.

19 M. Marcos, R. Alcalá, J. Barberá, P. Romero, C. Sánchez and J. L. Serrano, Chem. Mater., 2008, 20, 5209-5217.

20 (a) G. Bellachioma, G. Ciancaleoni, C. Zuccaccia, D. Zuccaccia and A. Macchioni, Coord. Chem. Rev., 2008, 252, 2224-2238; (b) I. Fernandez, E. Martinez-Viviente and P. S. Pregosin, Inorg. Chem., 2005, 44, 5509-5513; (c) P. S. Pregosin, Prog. Nucl. Magn. Reson. Spectrosc., 2006, 49, 261-288.

21 (a) E. Boisselier, C. Ornelas, I. Pianet, J. R. Aranzaes and D. Astruc, Chem.-Eur. J., 2008, 14, 5577-5587; (b) C. Ornelas, E. Boisselier, V. Martinez, I. Pianet, J. R. Aranzaes and D. Astruc, Chem. Commun., 2007, 50935095.

22 J. M. Rueff, J. Barberá, B. Donnio, D. Guillon, M. Marcos and J. L. Serrano, Macromolecules, 2003, 36, 8368-8375. 